\title{
Simplification of Gibbs Free Energy Equation for Predicting the Gas Composition of Steam Gasification of Pattukku Coal Char
}

\author{
Takdir Syarif $^{1,2,}$, Hary Sulistyo ${ }^{2}$, Wahyudi Budi Sediawan ${ }^{2}$, and Budhijanto ${ }^{2}$ \\ 1 Chemical Engineering Department, Faculty of Industrial Technology, Moslem University of Indonesia \\ Jl. Urip Sumoharjo Km. 05 Makassar, Indonesia \\ 2 Chemical Engineering Department, Engineering Faculty, Gadjah Mada University \\ Jl. Grafika 2 Yogyakarta 55281, Indonesia \\ *E-mail: takdir_syarif@umi.ac.id (Corresponding author)
}

\begin{abstract}
One of the method to utilize coal as a source of fuel is to convert the coal into a synthetic gas through the process of gasification. The composition of the gas formed greatly depends on the gasification agent and the process conditions. Currently, some researchers have developed a mathematical model based on thermodynamics to predict the gasification gas composition, based on Gibbs free energy. The equations used to calculate the Gibbs free energy are relatively complex. This study proposes simpler equations to predict the gas compositions in the form of correlation of component's Gibbs free energy and temperature. The simpler equations proposed were then tested by the experimental data of steam gasification of Pattukku coal char. Base on the result of the experimental and calculation showed if the temperature of gasifier increase by $100{ }^{\circ} \mathrm{C}$, the volume of gas will increase by approximately 1.5 times. The largest average of error obtained for model 1 is $22.95 \%$ while from model 2 is $23.45 \%$. The calculation showed that the proposed model could quantitatively be applied to predict the gas composition of steam gasification of Pattukku coal char.
\end{abstract}

Keywords: Experimental data, gasification, Gibbs free energy, Pattukku coal char, thermodynamic model.

ENGINEERING JOURNAL Volume 21 Issue 7

Received 28 January 2017

Accepted 24 April 2017

Published 29 December 2017

Online at http://www.engj.org/

DOI:10.4186/ej.2017.21.7.29 


\section{Introduction}

Coal is largely available energy source in Indonesia. The deposits can be found in Sumatra, Kalimantan, Sulawesi, and West Papua. Unfortunately, those coals belong to low-grade energy resources (subbituminous) [1]. So in order to utilize it, upgrading is needed. One of the methods to upgrade the quality of the coal as an energy source is gasification to produce synthetic gas [2]. Gasification is a thermal process that converts raw materials containing carbon into the flammable gas. In the coal gasification, coal or charcoal was reacted with gasification agents such as oxygen, steam or $\mathrm{CO}_{2}[3,4]$. The composition of the formed gas depends greatly on the gasification agent and the operating conditions [5]. When gasification using $\mathrm{CO}_{2}$ is run at a temperature of $900^{\circ} \mathrm{C}$, the gas produced will be dominated by the $\mathrm{CO}$ and $\mathrm{CO}_{2}[6,7]$. Whereas when using the steam, then the most widely produced gas is $\mathrm{H}_{2}$ and $\mathrm{CO}_{2}$.

In the design and operation of the gasification process, the understanding of the influence of raw material and other operating parameters are required. For this reason, mathematical equations or modeling that could be used to perform the optimization of the process is of importance $[8,9,10,11]$. Some researchers already proposed modeling the process of gasification by using the equilibrium approach. Sharma [12], used thermodynamic modeling and kinetics of the reduction reaction of char in the biomass downdraft gasifier. Zainal et al., [13]; Sharma [14], used the equilibrium model for predicting the distribution of the various types of gas. Florin et al., [15] studied the influence of thermodynamic equilibrium in the formation of hydrogen through gasification of biomass with steam. Jarungthammachote and Dutta [16], developed a thermodynamic equilibrium model based on the equilibrium constants to predict the gas composition in a downdraft gasifier.

In the calculation process, some researchers have used the NASA polynomial equation to the calculation of [17].

$$
\frac{\Delta G^{o}{ }_{i}}{R \cdot T}=A g_{i}+B g_{i} \cdot T+C g_{i} \cdot T^{2}+D g_{i} \cdot T^{3}+E g_{i} \cdot T^{4}+\frac{F g_{i}}{T}+G g_{i} \cdot \ln T
$$

The equation is considered relatively complex because it has seven parameters. Therefore, this study aims to find simpler equations. The study includes laboratory experiments to generate gas composition data of the char gasification process at different temperature and thermodynamics analysis to develop a simple model for predicting the gasification gas composition. The char studied were obtained from Pattukku coal pyrolysis product. In addition, the study also aims to observe the influence of the temperature on the gas volume of gasification products.

\section{Gasification Model}

The process of gasification usually performed at high temperatures. So in this study, the reaction is assumed to be spontaneous. According to Bell et al., [6], if the residence time in the gasifier is longer than the reaction time, then the product will be out of a gasifier in a state of equilibrium. Thus, the equilibrium thermodynamic approaches could be used in predicting the gasification gas composition. A nonstoichiometry model is one approach that could be used in the determination of the composition of gasification products when the reaction mechanism is unknown $[18,19]$. This model uses a Gibbs free energy minimization approach through Lagrange multiplier and does not require reactions formula in the calculation process.

In the equilibrium, total Gibbs free energy of a system is minimum [20]. Consequently,

$$
\left.d G^{t}\right|_{T, P}=0
$$

At a certain temperature and pressure, the total Gibbs free energy of a single phase in system with multi-components was defined by [21]:

$$
\left.G^{t}\right|_{T, P}=\sum_{i=1}^{m} n_{i}\left(\frac{\partial G^{t}}{\partial n_{i}}\right)_{T, P, n_{j}}
$$


where $\left.G^{t}\right|_{T, P}$ are the total Gibbs free energy of a system and ni is mole of each species in the gas product, $\mathrm{m}$ is the number of components in the gas product.

The value of $\left(\frac{\partial G^{t}}{\partial n_{i}}\right)_{T, P, n_{j}}$ is known as the chemical potential $\mu \mathrm{i}$ that can be expressed as :

$$
\mu_{i}=\Delta G_{i}^{o}+R \cdot T \cdot \ln \left(\frac{f_{i}}{f_{i}^{o}}\right)
$$

Equation (4) can also be expressed in the form of:

$$
\mu_{i}=\Delta G_{i}^{o}+R \cdot T \cdot \ln \left(\frac{\phi \cdot P_{i}}{P^{o}}\right)
$$

If all the gasses are considered as ideal gasses then fugacity ratio could be replaced by number of mole of the species:

$$
\mu_{i}=\Delta G_{i}^{o}+R \cdot T \cdot \ln \left(\frac{n_{i}}{\sum_{i}^{m} n_{i}}\right)
$$

The combination of Eq. (6) and Eq. (3) results in:

$$
G^{t}=\sum_{i=1}^{N} n_{i} \cdot \Delta G_{i}^{o}+R \cdot T \cdot n_{i} \cdot \ln \left(\frac{n_{i}}{\sum_{i}^{m} n_{i}}\right)
$$

Equation (7) could be partially differentiated against the number of mole of each species i. It is obtained that:

$$
\left(\frac{\partial G^{t}}{\partial n_{i}}\right)_{T, P, n_{j}}=\frac{\Delta G_{i}^{o}}{R \cdot T}+\ln \left(\frac{n_{i}}{\sum_{i}^{m} n_{i}}\right)
$$

In order to get $\left.d G^{t}\right|_{T, P}=0$, the value of

$$
\left(\frac{\partial G^{t}}{\partial n_{i}}\right)_{T, P, n_{j}}=0
$$

for all $\mathrm{i}=1,2,3, \ldots ., \mathrm{nm}$ (Eq. (8)). So the minimization of $\left.G^{t}\right|_{T, P}$ can be conducted by solving simultaneous Eqs. of (9) for all i. 


\section{Mass Balance}

To calculate the number of moles of each component, the constraints of mass balance can be utilized. Based on the concept of mass balance, the mass of each element is conserved. The mass balance of component $i$ can be written as follows:

$$
U_{j}-\sum_{i=1}^{m} a_{i j} \cdot n_{i}=0, \quad(j=1,2,3, \ldots \ldots \ldots . . . k)
$$

\section{Lagrange Multiplier}

To solve Eq. (9) using constraint in Eq. (10) the Lagrange Multiplier method is applied. In this method of minimization of Gt with the constraint of Eq. (10) can be done by simultaneously solving Eqs. (9) and (10):

$$
\begin{aligned}
& \frac{\Delta G_{1}^{o}}{R . T}+\ln \left(\frac{n_{1}}{n_{g}}\right)+\lambda_{1} \frac{\partial U_{1}}{\partial n_{1}}+\lambda_{2} \frac{\partial U_{2}}{\partial n_{1}}+\lambda_{3} \frac{\partial U_{3}}{\partial n_{1}}+\ldots . .+\lambda_{k} \frac{\partial U_{k}}{\partial n_{1}}=0 \\
& \frac{\Delta G_{2}^{o}}{R . T}+\ln \left(\frac{n_{2}}{n_{g}}\right)+\lambda_{1} \frac{\partial U_{1}}{\partial n_{2}}+\lambda_{2} \frac{\partial U_{2}}{\partial n_{2}}+\lambda_{3} \frac{\partial U_{3}}{\partial n_{2}}+\ldots . .+\lambda_{k} \frac{\partial U_{k}}{\partial n_{2}}=0 \\
& \frac{\Delta G_{3}^{o}}{R . T}+\ln \left(\frac{n_{3}}{n_{g}}\right)+\lambda_{1} \frac{\partial U_{1}}{\partial n_{3}}+\lambda_{2} \frac{\partial U_{2}}{\partial n_{3}}+\lambda_{3} \frac{\partial U_{3}}{\partial n_{3}}+\ldots . .+\lambda_{k} \frac{\partial U_{k}}{\partial n_{3}}=0 \\
& \frac{\Delta G_{m}^{o}}{R . T}+\ln \left(\frac{n_{m}}{n_{g}}\right)+\lambda_{1} \frac{\partial U_{1}}{\partial n_{m}}+\lambda_{2} \frac{\partial U_{2}}{\partial n_{m}}+\lambda_{3} \frac{\partial U_{3}}{\partial n_{m}}+\ldots . .+\lambda_{k} \frac{\partial U_{k}}{\partial n_{m}}=0
\end{aligned}
$$

The solution gives the value of $\mathrm{n}_{1}, \mathrm{n}_{2}, \ldots ., \mathrm{nm}, \lambda_{1}, \lambda_{2}, \ldots . ., \lambda_{\mathrm{k}}$.

The simultaneous equations formed from Eq. (11) in the form of mole fraction $\left(y_{i}\right)$ are as follows:

$$
\begin{gathered}
\frac{\Delta G_{C H 4}^{o}}{R \cdot T}+\ln \left(y_{C H 4}\right)+\lambda_{C}+4 \lambda_{H}=0 \\
\frac{\Delta G_{C O}^{o}}{R \cdot T}+\ln \left(y_{C O}\right)+\lambda_{C}+\lambda_{O}=0 \\
\frac{\Delta G_{H 2}^{o}}{R \cdot T}+\ln \left(y_{H 2}\right)+2 \lambda_{H}=0 \\
\frac{\Delta G_{C O 2}^{o}}{R \cdot T}+\ln \left(y_{C O 2}\right)+\lambda_{C}+2 \lambda_{O}=0 \\
\frac{\Delta G_{H 2 O}^{o}}{R . T}+\ln \left(y_{H 2 O}\right)+\lambda_{H}+2 \lambda_{O}=0
\end{gathered}
$$


Equation (10) and Eqs. (12a) to (12e) can be solved simultaneously by using Newton-Raphson method.

\section{Model Formulation of $\frac{\Delta G_{i}^{o}}{R \cdot T}$}

To simultaneously solve Eqs. (10) and (12a) to (12e), the correlation between $\frac{\Delta G_{i}^{o}}{R . T}$ and temperature (T) are needed. For the purpose, NASA polynomials are available. However, the polynomials are relatively complex. In this study two types of simpler correlations for $\frac{\Delta G_{i}^{o}}{R \cdot T}$ are proposed, which are as the following:

\subsection{Model 1}

By definition in the literature [20]:

$$
\frac{\partial\left(\frac{\Delta G_{i}}{R T}\right)}{\partial T}=-\frac{\Delta H_{i}}{R T^{2}}
$$

By integration Eq. (13), will be retrieved:

$$
\frac{\Delta G_{i}^{o}}{R T}=\frac{\Delta G_{i, R}^{o}}{R T_{R}}-\int_{T_{R}}^{T} \frac{\Delta H_{i}}{R T^{2}} \partial T
$$

where

$$
\Delta H_{i}=\Delta H_{i, R}+\int_{T_{R}}^{T} C p_{i} d T
$$

If used the Cpi average, integration of Eq. (15) will be:

$$
\Delta H_{i}=\Delta H_{i, R}+C p_{i}\left(T-T_{R}\right)
$$

Substitution Eq. (16) into Eq. (14) will be:

$$
\frac{\Delta G_{i}^{o}}{R T}=\frac{\Delta G_{i, R}^{o}}{R T_{R}}+\left(\frac{C p_{i} T_{R}-\Delta H_{i, R}}{R}\right)_{T_{R}}^{T} \frac{1}{T^{2}} d T-\frac{C p_{i}}{R} \int_{T_{R}}^{T} \frac{1}{T} \partial T
$$

By completing Eq. (17), will be retrieved:

$$
\frac{\Delta G_{i}^{o}}{R T}=\frac{\Delta G_{i, R}^{o}}{R T_{R}}+\frac{C p_{i} T_{R}-\Delta H_{i, R}}{R T_{R}}-\left(\frac{C p_{i} T_{R}-\Delta H_{i, R}}{R T_{R}}\right)\left(\frac{T_{R}}{T}\right)+\frac{C p_{i}}{R} \ln \left(\frac{T_{R}}{T}\right)
$$

Furthermore, Eq. (18) can write in the simpler model as follows:

$$
\frac{\Delta G_{i}^{o}}{R T}=a_{1}+b_{1}\left(\frac{T_{R}}{T}\right)
$$


where

$$
\begin{gathered}
a_{1}=\frac{\Delta G_{i, R}^{o}}{R T_{R}}+\frac{C p_{i} T_{R}-\Delta H_{i, R}}{R T_{R}} \\
b_{1}=\frac{\Delta H_{i, R}}{R T_{R}}
\end{gathered}
$$

\subsection{Model 2}

Based on the relationship between $\frac{\Delta G_{i}^{o}}{R T}$ versus $\frac{T_{R}}{T}$ in the literature [11], the equation of $\frac{\Delta G_{i}^{o}}{R T}$ as function of $\frac{T_{R}}{T}$ can be expressed in the form:

$$
\frac{\Delta G_{i}^{o}}{R T}=a_{2}+b_{2} \exp \left(-\frac{T_{R}}{T}\right)
$$

The parameters $a_{1}, b_{1}$, or $a_{2}, b_{2}$ in Eqs. (19) and (20) can be obtained by curve fitting in which the value of Sum of Square of Error (SSE):

$$
S S E=\sum_{i=1}^{n}\left(\frac{y_{i_{-} \text {data }}-y_{i-\text { calculate }}}{y_{i-\text { data }}}\right)^{2}
$$

is to be minimized. The calculation flow chart is as in Fig. 1. 


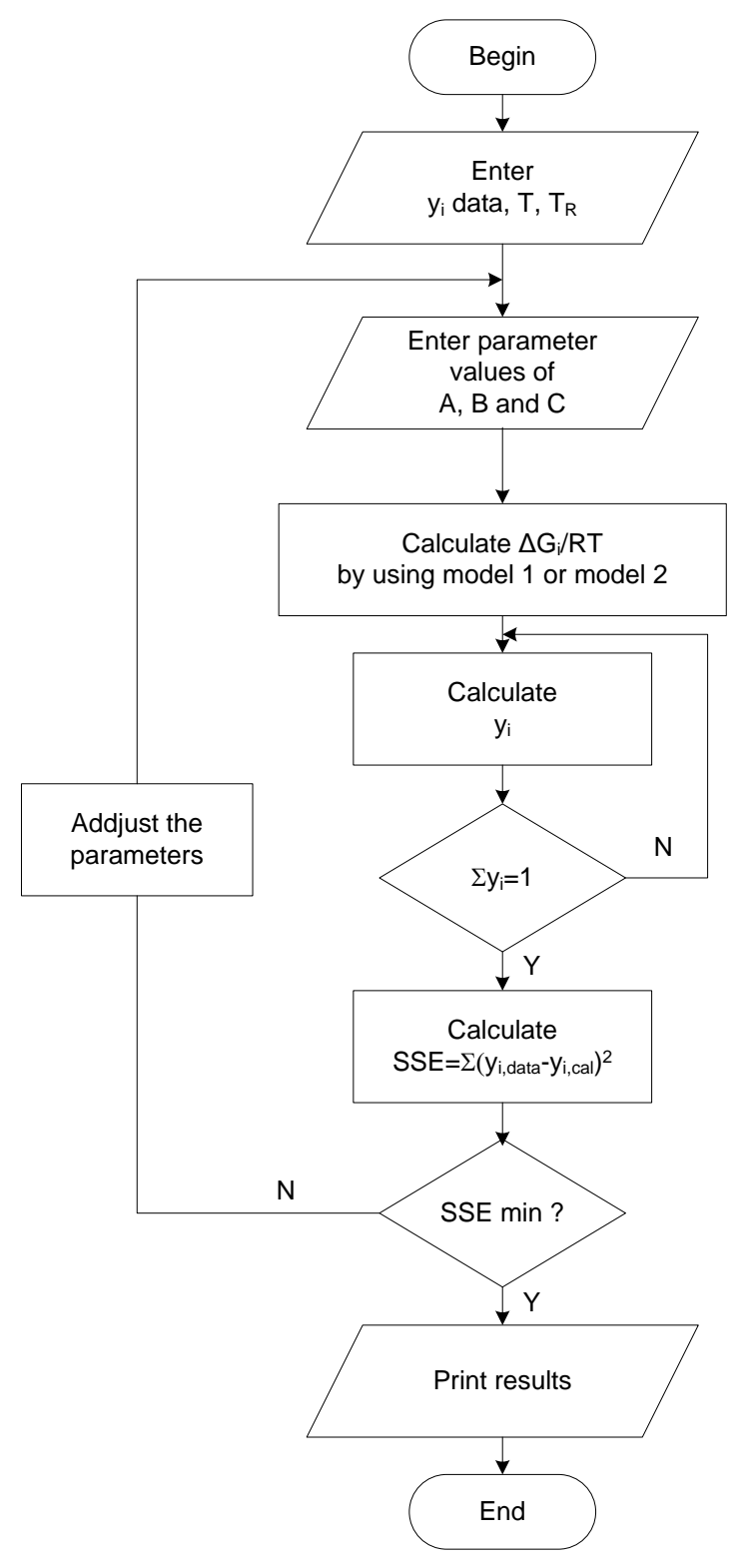

Fig. 1. Calculation flow chart of the model.

\section{Experimental Setup}

\subsection{Preparation of Char}

The raw material used in the research is char produced by pyrolysis of Pattukku coal obtained from Lappariaja area, district of Bone South Sulawesi. The pyrolysis was conducted in a quartz tubular reactor with a diameter of $3.5 \mathrm{~cm}$ and a height of $55 \mathrm{~cm}$ at $450{ }^{\circ} \mathrm{C}$ and $1 \mathrm{~atm}$. A schematic diagram of the pyrolysis equipment is shown in Fig. 2.

One hundred grams of Pattukku coal with a particle size of 3.35-4 $\mathrm{mm}$ were fed to the reactor. Before the process started, nitrogen gas was flowed from the bottom of the reactor to eliminate the existing air in the reactor. The Pyrolysis was started by switching on the electric furnace to heating the reactor. The pyrolysis experiment was carried out at fixed temperature $\left(450{ }^{\circ} \mathrm{C}\right)$ with a heating rate of $30{ }^{\circ} \mathrm{C} /$ minutes. After the temperature reached $450{ }^{\circ} \mathrm{C}$, the temperature controller was turned on and the isothermal process was held for 60 minutes. After that, the reactor was left 
until the temperature reached $30{ }^{\circ} \mathrm{C}$. The elemental composition of proximate and ultimate analysis of the coal and the char obtained are presented in Table 1.

Table 1. Proximate and Ultimate analysis results.

\begin{tabular}{|c|c|c|c|c|c|c|c|c|}
\hline \multicolumn{4}{|c|}{$\begin{array}{c}\text { Proximate analysis (\%) } \\
\text { of the coal }\end{array}$} & \multicolumn{5}{|c|}{$\begin{array}{c}\text { Ultimate analysis (\%) } \\
\text { of the char }\end{array}$} \\
\hline VM & FC & Moisture & Ash & C & $\mathrm{H}$ & $\mathrm{O}$ & $\mathrm{N}$ & $\mathrm{S}$ \\
\hline 38.28 & 47.92 & 4.7 & 10.80 & 68.93 & 2.99 & 24.39 & 1.81 & 1.88 \\
\hline
\end{tabular}

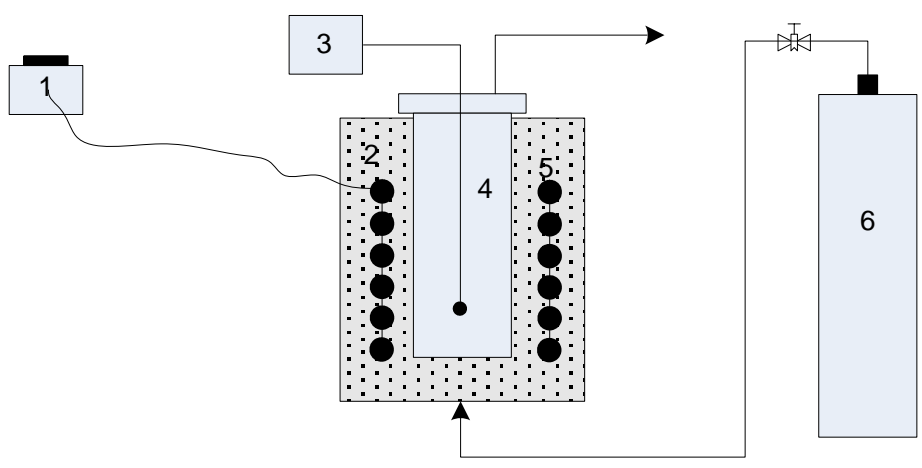
1. Regulator
4. Reactor
2. Isolator
5. Coil heater
3. Thermocouple
6. Nitrogen tank

Fig. 2. The schematic diagram of the pyrolysis apparatus.

\subsection{Gasification Process}

The schematic diagram of the gasification equipment is presented in Fig. 3. In the gasification process, $10 \mathrm{~g}$ of char was fed into the gasifier for each experiment. Before the process started, nitrogen was flowed from the bottom of the reactor to remove oxygen from the reactor. The experiment was started by switching on the electric furnace to increase the temperature of the gasifier. After the desired temperature was reached, steam flowed from the bottom of the reactor at the rate of $5 \mathrm{~mL} /$ minute. The non-condensed gas product was collected continuously in a tank containing water after it passed through the condenser. The volume of the gas collected at the various time was measured. Gasification process was carried out for 60 minutes, in which every 15 minutes, samples were taken for analysis. The concentration of $\mathrm{CH}_{4}, \mathrm{CO}, \mathrm{H}_{2}$ and $\mathrm{CO}_{2}$ were measured with gas chromatography. 


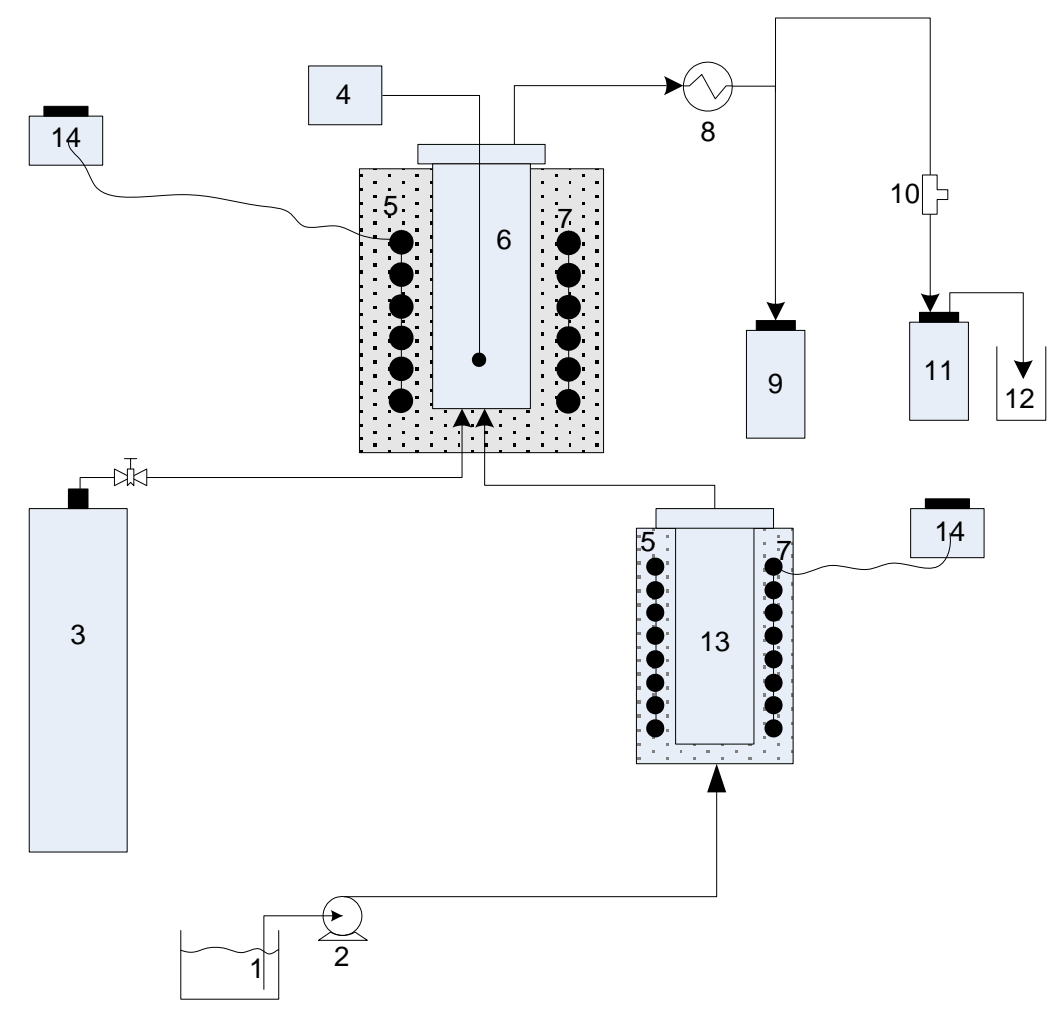

1. Water tank

8. Condenser

2. Pump

9. Condensate tank

3. Nitrogen tank

10. Sampling gas

4. Thermocouple

11. Water tank

5. Coil heater

12. Water reservoir

6. Reactor

13. Steamer

7. Isolator

14. Regulator

Fig. 3. The schematic diagram of the experimental apparatus.

\section{Result and Disscussion}

\subsection{Effect of Temperature on the Gas Volume}

In this study, the gasification process was run until 60 minutes in a three different temperatures, i.e. 600 , 700 , and $800{ }^{\circ} \mathrm{C}$. Data obtained include the amount of gas produced and the composition of the four main gasses $\mathrm{CH}_{4}, \mathrm{CO}, \mathrm{H}_{2}$, and $\mathrm{CO}_{2}$. The volume of gas produced at any time was presented in Fig. 4. 


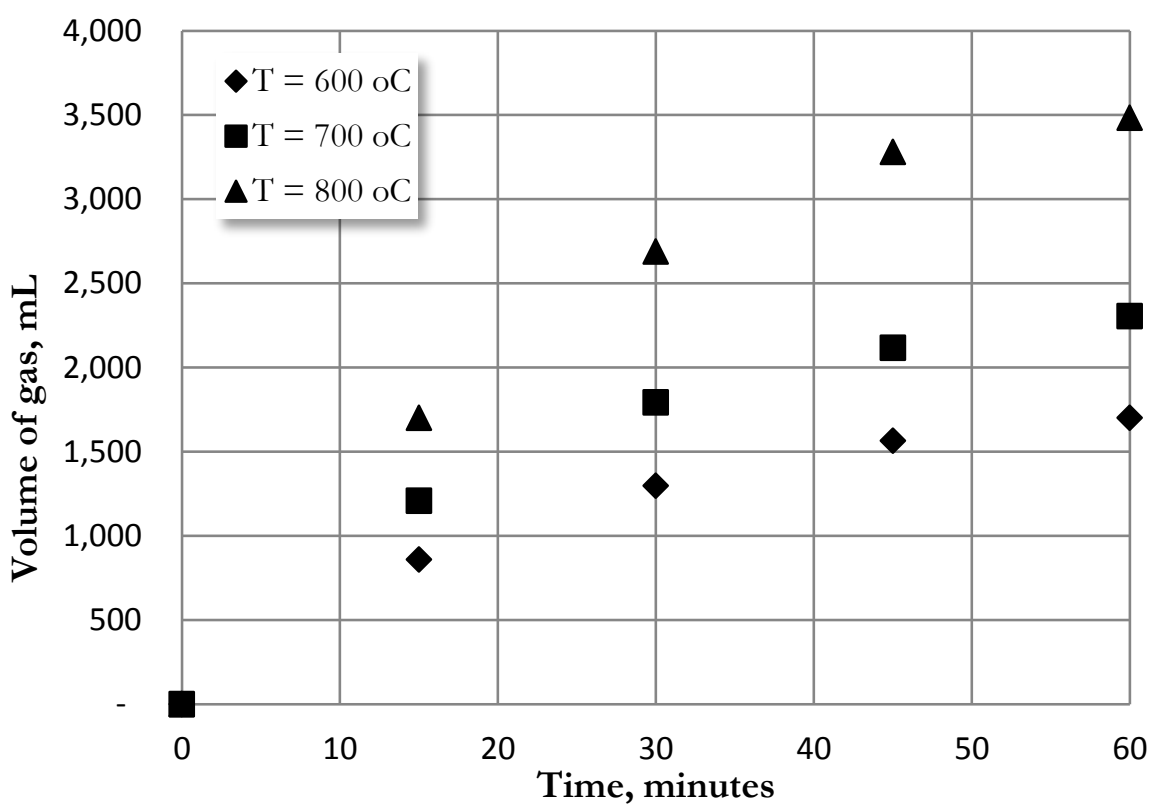

Fig. 4. The relationship between the volume of gas and time at gasification temperature of 600,700 , and $800^{\circ} \mathrm{C}$.

Figure 4 shows the gas volume varies with time at gasification temperature of 600,700 , and $800{ }^{\circ} \mathrm{C}$. It is seen that in general, the volume of gas produced will increase each time and a significant increase occurs until 45 minutes and then the gas volume will be steady.

Furthermore, Fig. 4 also shows that the increase of the temperature results in the increase of the volume of gas produced. The total volume of gas produced at a temperature of 600,700 , and $800{ }^{\circ} \mathrm{C}$ is 1701,2305 , and $3483 \mathrm{~mL}$ respectively. This significant volume increase shows that the reactor temperature significantly affects the rate of the gasification process. The increase was caused by the reaction between char and steam that are endothermic. So by adding heat into the reactor, the reaction will shift toward products.

\subsection{Effect of temperature on the gas composition}

Figures 5 show the effect of the gasifier temperature on the gas compositions. As shown in Fig. 5, the mol fraction of $\mathrm{CH}_{4}$ decreases with the increase of the temperature. At a temperature of $600{ }^{\circ} \mathrm{C}$, mole fraction of $\mathrm{CH}_{4}$ was $0.224 \%$ and decreased to $0.156 \%$ at a temperature of $700^{\circ} \mathrm{C}$. While at a temperature of $800^{\circ} \mathrm{C}$ mol fraction was $0.146 \%$. It is caused by methanation reaction that is exothermic.

The mole fraction of $\mathrm{H}_{2}$ increases with the increase of the temperature because the reaction between char and steam to produce hydrogen (water gas reaction) is endothermic. So the higher temperature will shift the equilibrium reaction to produce more hydrogen. This indicates that the temperature of the gasifier has an important role in the composition of gas produced by gasification.

From Fig. 5, it seems that the mole fraction of $\mathrm{CO}$ increases with the increase of the temperature. At a temperature of $600{ }^{\circ} \mathrm{C}$, mole fraction of CO was $6.83 \%$ and increased to $8.7 \%$ at a temperature of $700{ }^{\circ} \mathrm{C}$ and $12.39 \%$ at a temperature of $800{ }^{\circ} \mathrm{C}$. However, the increase of mole fraction of $\mathrm{CO}$ from $700{ }^{\circ} \mathrm{C}$ to $800{ }^{\circ} \mathrm{C}$ was approximately two times larger than the increase of the one from $600{ }^{\circ} \mathrm{C}$ to $700{ }^{\circ} \mathrm{C}$. In addition, the increase of mole fraction of $\mathrm{CO}_{2}$ from $700{ }^{\circ} \mathrm{C}$ to $800{ }^{\circ} \mathrm{C}$ was smaller than the one from $600{ }^{\circ} \mathrm{C}$ to $700{ }^{\circ} \mathrm{C}$. Water-gas shift reaction is exothermic thus the reaction equilibrium will shift to produces more $\mathrm{CO}$ and less $\mathrm{CO}_{2}$ by increasing temperature. 

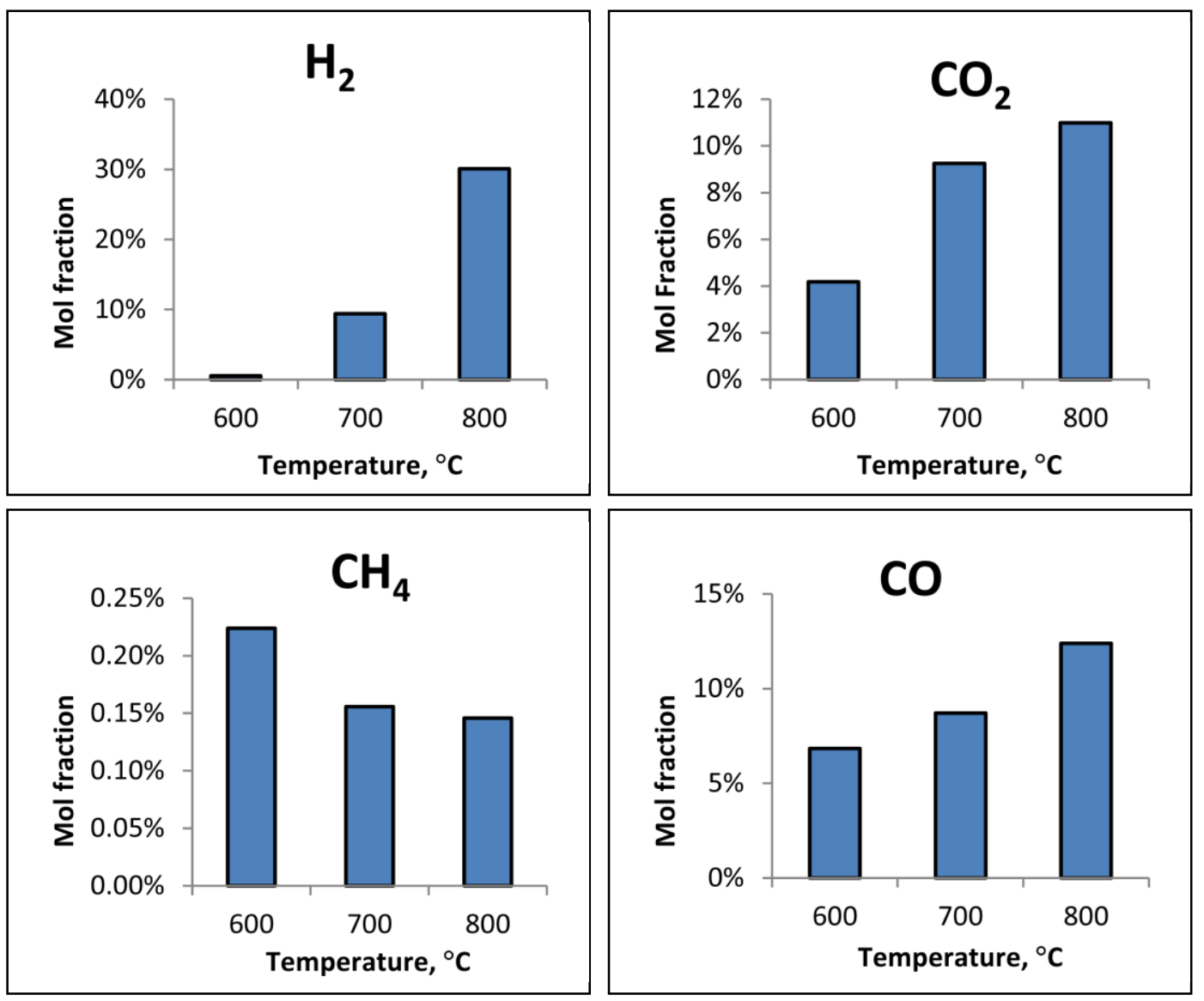

Fig. 5. Effect of temperature on the gas composition at 600,700 , and $800{ }^{\circ} \mathrm{C}$ for 60 minutes.

\subsection{Thermodynamic Analysis}

To generalize the experimental result, thermodynamics equilibrium model was applied. Since the temperature was relatively high, the reaction rates were assumed to be fast, so the equilibrium was attained. The gas composition was approximated by thermodynamics equilibrium approach as in Eqs. (10), (12), (13) and (14).

To get the values of the parameters in the equation, curve fitting method was applied. The gas compositions obtained from the calculation were compared to the gas composition from the laboratory experiment. The values of the parameters chosen were the ones that give the minimum value of the sum of squares of errors between the calculated and experimental data (Eq. (16)).

The values of the parameters obtained for model 1 and model 2 are presented in Table 2. Meanwhile, the comparison of calculated results and the experimental values was presented in Figs. 6a-6c and 7a-7c.

Table 2. The parameter values of model 1 and 2 .

\begin{tabular}{lrrrr}
\hline \multirow{2}{*}{ Component } & \multicolumn{4}{c}{ The equation parameter } \\
\cline { 2 - 5 } & \multicolumn{3}{c}{ Model 1 } & \multicolumn{1}{c}{ Model 2 } \\
\cline { 2 - 5 } & \multicolumn{1}{c}{$\mathbf{a}_{\mathbf{1}}$} & \multicolumn{1}{c}{$\mathbf{b}_{\mathbf{1}}$} & \multicolumn{1}{c}{$\mathbf{b}_{\mathbf{2}}$} \\
\hline $\mathrm{CH} 4$ & -17.4685 & 3.1156 & -19.4312 & 24.001 \\
$\mathrm{CO}$ & -19.5351 & -19.8290 & -45.1244 & 28.4406 \\
$\mathrm{H} 2$ & 10.9054 & -5.2005 & 9.3508 & -15.3774 \\
$\mathrm{CO} 2$ & -75.0775 & -28.9851 & -124.6406 & 101.5045 \\
$\mathrm{H} 2 \mathrm{O}$ & -143.5496 & 16.5224 & -171.8075 & 196.3864 \\
\hline
\end{tabular}




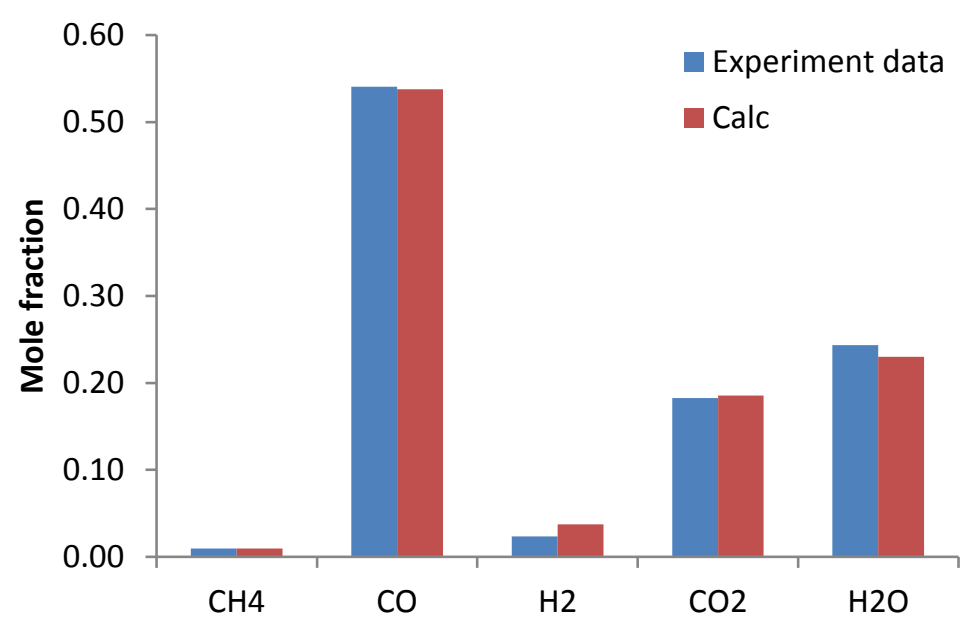

Fig. 6a. Comparison of mole fraction from thermodynamics model and experimental data at gasification temperature $600^{\circ} \mathrm{C}$ for model 1 .

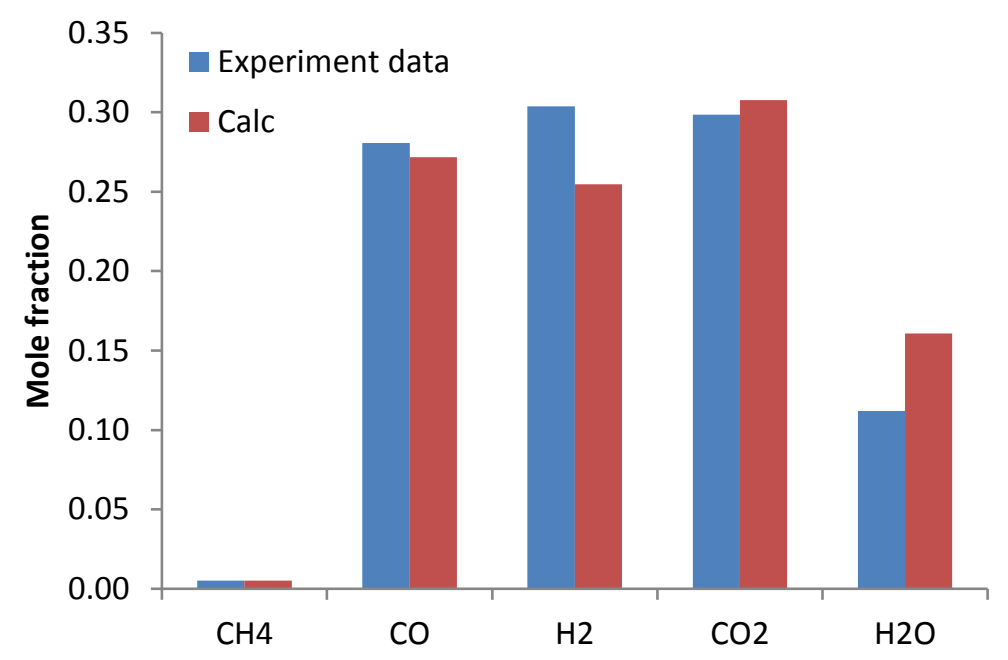

Fig. 6b. Comparison of mole fraction from thermodynamics model and experimental data at gasification temperature $700{ }^{\circ} \mathrm{C}$ for model 1 .

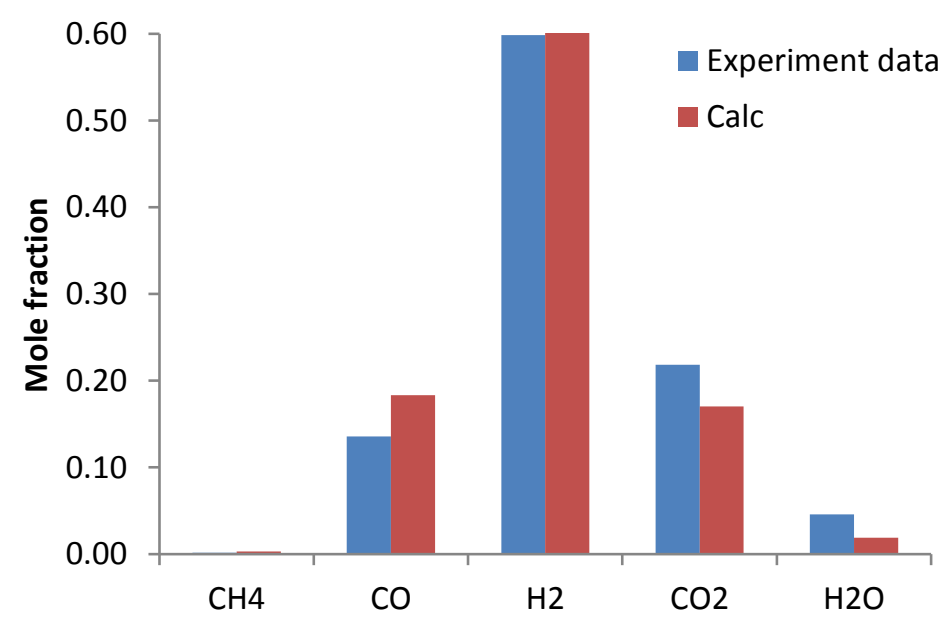

Fig. 6c. Comparison of mole fraction from thermodynamics model and experimental data at gasification temperature $800{ }^{\circ} \mathrm{C}$ for model 1 
Figures $6 a-6 c$ show a comparison of mole fraction from the experimental result and mole fraction from calculation result by using model 1. It is shown from Figs. 6a-6c that the calculated gas compositions by model 1 and the experimental data were matched with the largest average error was $22.95 \%$ at the temperature of $700{ }^{\circ} \mathrm{C}$ while the smallest average of error was $8.09 \%$ at the temperature of $600{ }^{\circ} \mathrm{C}$. Sum of Squares of Errors obtained from the calculation at a temperature of 600,700 , and $800{ }^{\circ} \mathrm{C}$ were $0.130,0.522$, and 0.174 respectively.

Figures $7 \mathrm{a}-7 \mathrm{c}$ show a comparison of mole fraction from the experimental result and mole fraction from calculation result by using model 2. It is shown from Figs. 7a-7c that the calculated gas compositions by model 2 and the experimental data were matched with the largest average error was $23.45 \%$ at the temperature of $700{ }^{\circ} \mathrm{C}$ while the smallest average of error was $8.41 \%$ at the temperature of $600{ }^{\circ} \mathrm{C}$. Sum of Squares of Errors obtained from the calculation at a temperature of $600{ }^{\circ} \mathrm{C}, 700{ }^{\circ} \mathrm{C}$, and $800{ }^{\circ} \mathrm{C}$ were 0.118 ; 0.569 dan 0.213 respectively.

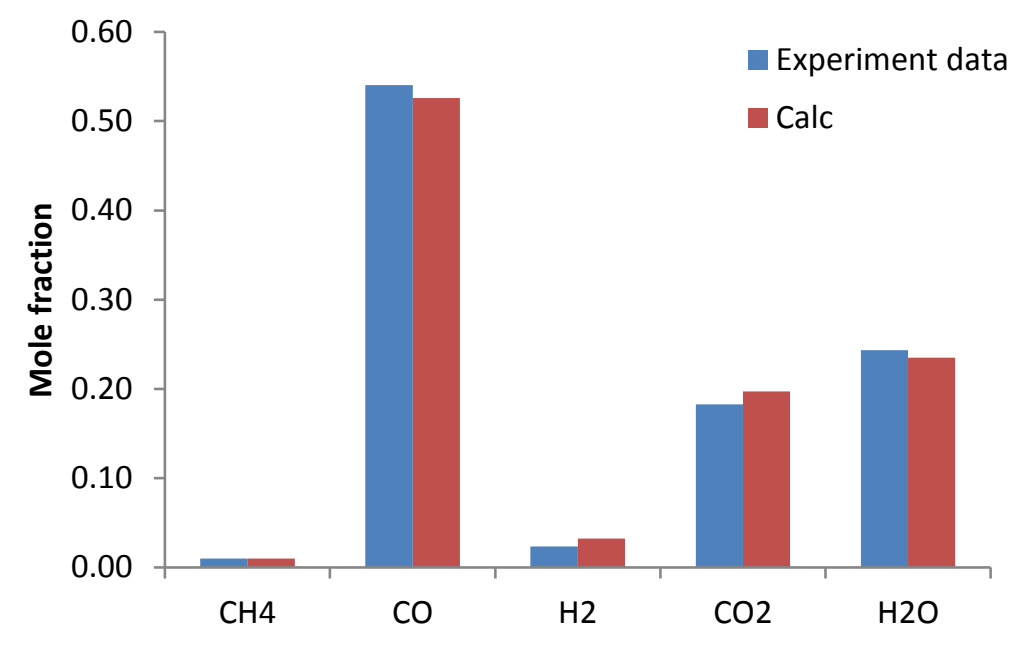

Fig. 7a. Comparison of mole fraction from thermodynamics model and experimental data at gasification temperature $600{ }^{\circ} \mathrm{C}$ for model 2 .

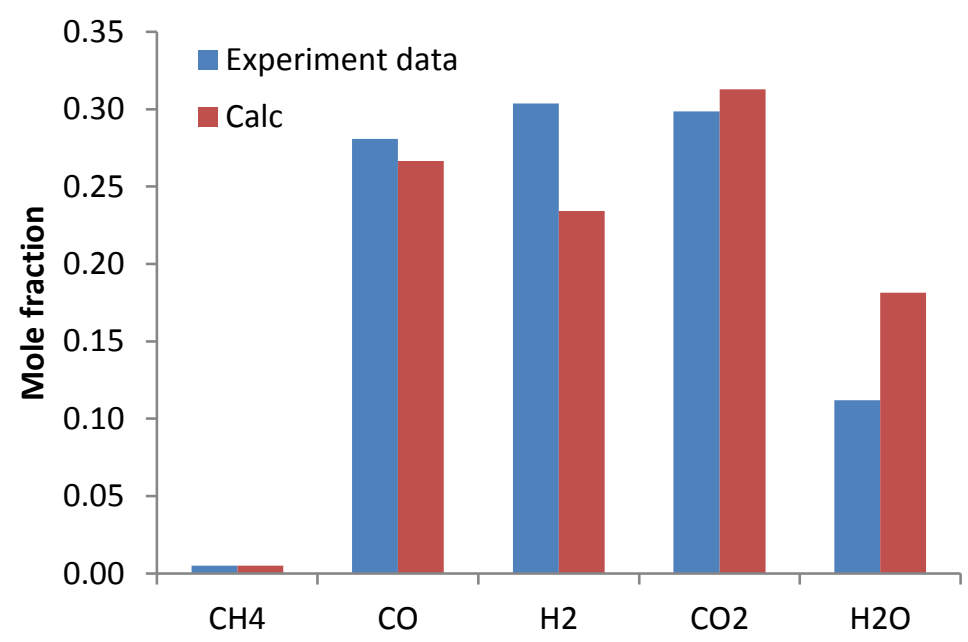

Fig. 7b. Comparison of mole fraction from thermodynamics model and experimental data at gasification temperature $700{ }^{\circ} \mathrm{C}$ for model 2 . 


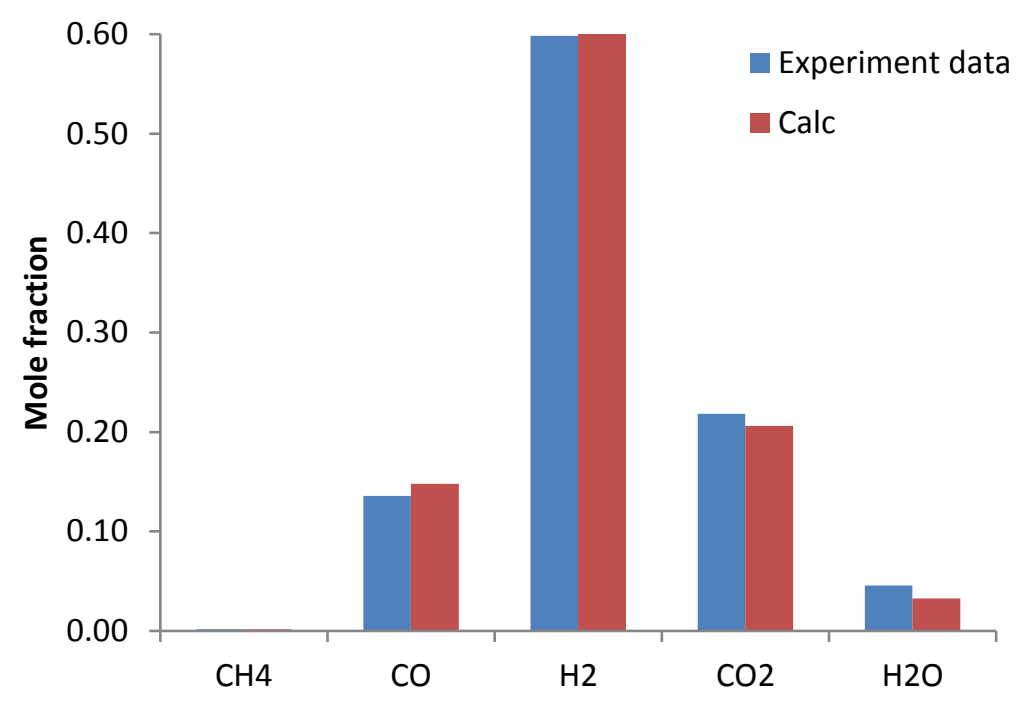

Fig. 7c. Comparison of mole fraction from thermodynamics model and experimental data at gasification temperature $800{ }^{\circ} \mathrm{C}$ for model 2 .

The deviations of the results of model 1 and model 2 to experimental data for all components and temperatures are presented in Figs. 8 and 9. It can be visually observed that the models 1 and 2 were matched to experimental data.

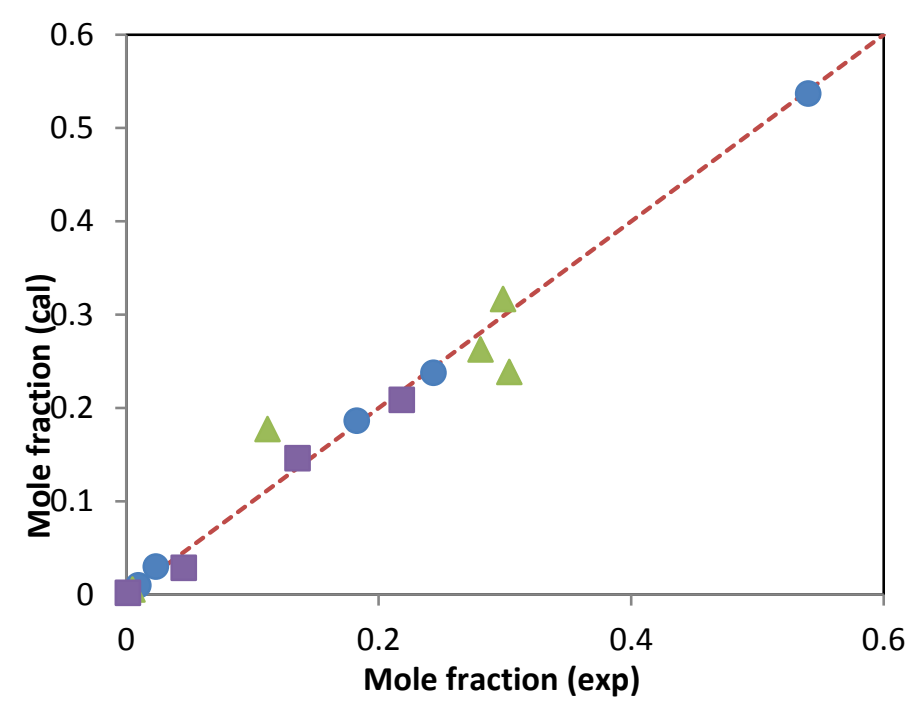

Fig. 8. The deviation of model 1 results to experimental data for all temperatures and gas components. 


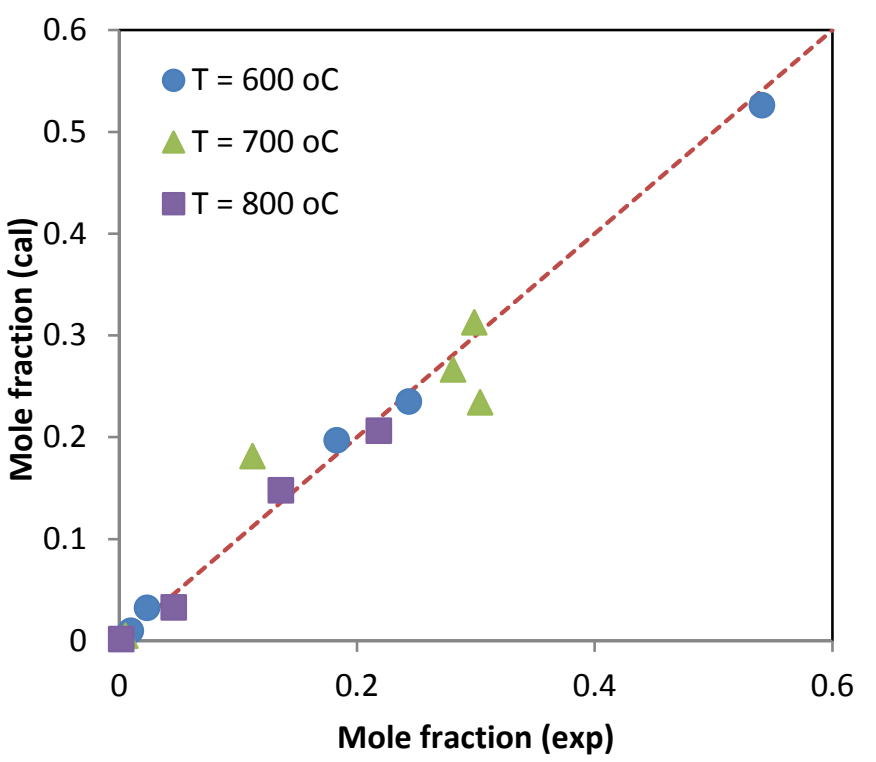

Fig. 9. The deviation of model 2 results to experimental data for all temperatures and gas components.

By comparing the values of the average of errors and Sum of Squares of Errors of model 1 and 2, it can be concluded that model 1 gives slightly better results than model 2 . Since the complexity of model 1 and model 2 are comparable, it is suggested the use of model 1. So, for practicality model 1 is suggested to be applied.

\section{Conclusions}

Based on the results of the calculation and experimental data, some conclusions could be obtained as follows:

a. Rising temperatures will increase the volume of gas product. The volume of gas will increase by approximately 1.5 times if the temperature of gasifier increases by $100{ }^{\circ} \mathrm{C}$.

b. Gibbs free energy models proposed could be used to predict the composition of gas produced from char gasification.

c. Although an average of error and SSE value for model 2 is greater than the one of model 1, model 2 is simpler than model 1.

\section{Acknowledgement}

The authors would like to thank Ministry of Research, Technology, and Higher Education, Republic of Indonesia for funding this research through BPPDN scholarship

\section{Nomenclature}

$\Delta \mathrm{G}_{\mathrm{i}}^{\mathrm{o}_{\mathrm{i}}} \quad$ Gibbs free energy species i $(\mathrm{J} / \mathrm{mol})$

$\mathrm{R} \quad$ universal gas constant $(\mathrm{J} / \mathrm{mol} . \mathrm{K})$

$\mathrm{T} \quad$ temperature $(\mathrm{K})$

$\mathrm{Ag}_{\mathrm{i}}-\mathrm{Gg}_{\mathrm{i}}$ constants in Eq. (1)

$\mu \mathrm{i} \quad$ chemical potential species $\mathrm{i}(\mathrm{J} / \mathrm{mol})$

$\mathrm{P}_{\mathrm{i}} \quad$ partial pressure species $\mathrm{i}(\mathrm{atm})$

Po total pressure species $\mathrm{i}(\mathrm{atm})$

$U_{j} \quad$ number of mole element $j$

$a_{i j} \quad$ number of atom element $j$ in species $i$

$\mathrm{n}_{\mathrm{i}} \quad$ mole species $\mathrm{i}(\mathrm{mol})$

$\mathrm{y}_{\mathrm{i}} \quad$ mole fraction species $\mathrm{i}$

$\lambda_{j} \quad$ Lagrange constants for element $j$

$a_{1}-b_{1} \quad$ constants in Eq. (14) 
$\mathrm{a}_{2}-\mathrm{b}_{2}$ constants in Eq. (15)

\section{References}

[1] Kementerian ESDM, "Indonesia: Mineral and Coal Information 2015," Directorate General of Mining and Coal, p. 37, 2015.

[2] P. Basu, Biomass Gasification and Pyrolysis. US: Elsevier, 2010.

[3] R. Luque and J. G. Speight, Gasification for Synthetic Fuel Production: Fundamentals, Processes and Applications. Elsevier, 2014.

[4] M. Rashid Khan, Advances in Clean Hydrocarbon Fuel Processing: Science and Technology. Woodhead Publishing Series in Energy, 2011.

[5] J. Rezaiyan and N. P. Cheremisinoff, Gasification Technologies, 1st ed. Francis: CRC Press, 2005.

[6] D. A. Bell, B. F. Towler, and M. Fan, Coal Gasification and Its Applications, 1st ed, vol. 1. Elsevier, 2011.

[7] S. Lin, M. Harada, Y. Suzuki, and H. Hatano, "Hydrogen production from coal by separating carbon dioxide during gasification," Fuel, vol. 81, no. 16, pp. 2079-2085, 2002.

[8] M. Materazzi, P. Lettieri, L. Mazzei, R. Taylor, and C. Chapman, "Thermodynamic modelling and evaluation of a two-stage thermal process for waste gasification," Fuel, vol. 108, pp. 356-369, 2013.

[9] P. Pintana and N. Tippayawong, "Predicting ash deposit tendency in thermal utilization of biomass," Engineering Journal, vol. 20, no. 5, pp. 15-24, 2016.

[10] C. Tangsathitkulchai, S. Junpirom, and J. Katesa, "Comparison of kinetic models for $\mathrm{CO}_{2}$ gasification of coconut-shell chars: Carbonization temperature effects on char reactivity and porous properties of produced activated carbons," Engingeering Journal, vol. 17, no. 1, pp. 13-28, 2016.

[11] A. Farooq, M. Ghauri, and K. Shahzad, "Modeling of biomass gasification with $\mathrm{CO}_{2}$ as gasifying agent," Sci. Int., vol. 25, no. 3, pp. 497-500, 2013.

[12] A. K. Sharma, "Equilibrium and kinetic modeling of char reduction reactions in a downdraft biomass gasifier: A comparison,” Sol. Energy, vol. 82, no. 10, pp. 918-928, 2008.

[13] Z. A. Zainal, R. Ali, C. H. Lean, and K. N. Seetharamu, "Prediction of performance of a downdraft gasifier using equilibrium modeling for different biomass materials," Energy Convers. Manag., vol. 42, no. 12, pp. 1499-1515, 2001.

[14] A. K. Sharma, "Equilibrium modeling of global reduction reactions for a downdraft ( biomass ) gasifier," Energy Conversion and Management, vol. 49, no. 4, pp. 832-842, 2008.

[15] N. H. Florin and A. T. Harris, "Hydrogen production from biomass coupled with carbon dioxide capture: The implications of thermodynamic equilibrium," Energy, vol. 32, no. 17, pp. 4119-4134, 2007.

[16] S. Jarungthammachote and A. Ã. Dutta, "Thermodynamic equilibrium model and second law analysis of a downdraft waste gasifier," Energy, vol. 32, no. 9, pp. 1660-1669, 2007.

[17] S. R. Turns, An Introduction to Combustion, 2nd ed. McGraw-Hill, 2000.

[18] B. Acharya, A. Dutta, and P. Basu, "An investigation into steam gasification of biomass for hydrogen enriched gas production in presence of $\mathrm{CaO}$," Int. J. Hydrogen Energy, vol. 35, no. 4, pp. 1582-1589, 2010.

[19] Q. Yan, L. Guo, and Y. Lu, "Thermodynamic analysis of hydrogen production from biomass gasification in supercritical water," Energy Convers. Manag., vol. 47, pp. 1515-1528, 2006.

[20] J. M. Smith, H. C. Van Ness, and M. M. Abbott, Introduction to Chemical Engineering Thermodynamics, 7th ed. McGraw-Hill, 2005.

[21] M. J. Moran, H. N. Shapiro, D. D. Boettner, and M. B. Bailey, Fundamentals of Engineering Thermodynamics, 7th ed. John Wiley \& Sons, 2011. 